\title{
The effects of growth factors on in vitro-cultured porcine testicular cells
}

\author{
Ewart W Kuijk, Ben Colenbrander and Bernard A J Roelen \\ Department of Farm Animal Health, Faculty of Veterinary Medicine, Utrecht University, Yalelaan 104, \\ 3584 CM Utrecht, The Netherlands \\ Correspondence should be addressed to B A J Roelen; Email: b.a.j.roelen@uu.nl
}

E W Kuijk is now at Department of Reproductive Medicine and Gynaecology, University Medical Center Utrecht, PO Box 85500, 3508 GA Utrecht, The Netherlands

\begin{abstract}
Cell lines from neonate porcine testis were cultured and characterized and the effect of growth factors were investigated, in order to determine the requirements for the establishment of porcine male germ cell lines. In primary cultures, three different colony types with distinctive morphologies could be recognized. From colonies resembling mouse spermatogonial stem cells (SSCs), two cell lines were derived and maintained for nine passages after which proliferation stopped. Growth of these cell lines depended on the growth factors leukemia inhibitory factor (LIF), epidermal growth factor (EGF), glial derived neurotrophic factor (GDNF), and fibroblast growth factor (FGF). In both cell lines NANOG, promyelocytic leukemia zinc-finger (PLZF), and EPCAM, were expressed at higher levels and GFRA1, ITGA6, and THY1 at lower levels than in neonate porcine testis. Primary cultures of neonate pig testis were subjected to a factorial design of the growth factors LIF, GDNF, EGF, and FGF. EGF and FGF had a positive effect on the number and size of the SSC-like colonies. Addition of EGF and FGF to primary cell cultures of neonate pig testis affected the expression of NANOG, PLZF, POU5F1, and GATA4, whereas effects of LIF or GDNF could not be detected. FGF decreased the expression levels of NANOG, a marker for pluripotency also expressed in neonatal porcine male germ cells. FGF decreased expression of PLZF and enhanced the expression of pluripotency-related gene POU5F1 and Sertoli cell marker GATA4. EGF had a positive effect on PLZFexpression levels and counteracted the positive effect of FGF on GATA4 expression. These results suggest that FGF can impede successful derivation of porcine SSCs from neonate pig testis.

Reproduction (2009) $138721-731$
\end{abstract}

\section{Introduction}

In developing mouse embryos, primordial germ cells (PGCs) originate from the proximal epiblast. PGCs concentrate at the base of the allantois and migrate via the hindgut mesentery towards the genital ridges (McLaren 2003). After colonizing the genital ridges, male germ cells become gonocytes and, after birth, gonocytes migrate to the basement membrane and differentiate into spermatogonial stem cells (SSCs; Brinster 2002). SSCs have a capacity of self-renewal and the potential to give rise to cell types that are committed to differentiate to spermatozoa in a complex process called spermatogenesis (Brinster 2002). In mammals, SSCs are unique because they are the only adult stem cells that can contribute to the next generation. Recent developments have shown that mouse SSCs can be isolated from pre-pubertal and adult testes, and cultured long-term in vitro without losing the capacity to restore fertility of infertile mice by transplantation into testes depleted of germ cells (Kanatsu-Shinohara et al.
2003, Kubota et al. 2004). It has also been demonstrated that in these cells, prior to transplantation, genes can be targeted through homologous recombination, which is an alternative to embryonic stem (ES)-cell-based gene targeting for directed genetic modification in mice (Kanatsu-Shinohara et al. 2006). In mammalian species other than mouse and human, where ample attempts to generate ES cell lines have had limited success, SSC based gene targeting is a promising technique for the production of transgenic offspring. Gene targeting would particularly mean a highly valuable tool in pigs because of their importance in agriculture and because the organ sizes and life span make pigs valuable model organisms for medical purposes.

Another interesting aspect of mouse SSC cultures is that in these cell lines ES-like cells are formed spontaneously. Pluripotency of these ES-like cells has been demonstrated by their capacity to contribute to germline chimeras (Kanatsu-Shinohara et al. 2004, Guan et al. 2006). Potentially, a similar approach 
could result in pluripotent ES-like cells from other species, such as pigs, from which pluripotent cell lines are not available yet.

Xenografting of testicular cells from a diversity of species has shown that porcine and other alien SSCs can colonize a recipient mouse testis (Dobrinski 2005). This suggests a conserved mechanism of self-renewal for these cell types between mammals (Dobrinski 2005). In the adult testis, Sertoli cells, Leydig cells, and peritubular myoid cells define a major part of the niche of SSCs. This microenvironment supports SSCs by providing essential external stimuli such as growth factor stimulation (Oatley \& Brinster 2008). In the testis, FSH stimulates Sertoli cells to produce glial derived neurotrophic factor (GDNF), an essential growth factor that supports SSC function (Tadokoro et al. 2002, Naughton et al. 2006). In mice, SSC self-renewal depends on GDNF signaling through the RET tyrosine kinase/GFRA1 receptor complex (Naughton et al. 2006). Self-renewal of SSCs in in vitro cultures depends on GDNF in combination with either basic fibroblast growth factor (FGF) or epidermal growth factor (EGF; KanatsuShinohara et al. 2005). Leukemia inhibitory factor (LIF), an important growth factor in mouse ES cells, has also been reported to be an essential growth factor that supports SSC-self renewal (Guan et al. 2006). Proliferation of SSCs in vitro cultures is enhanced by the addition of FGF (Kubota et al. 2004). For these reasons, SSCs are generally cultured in the presence of LIF, GDNF, EGF, and FGF. However, the presence of FGF, EGF, and LIF for the initial culture of testicular cells may also result in the overgrowth of somatic cells, such as fibroblasts, endothelial cells, and Sertoli cells (Guan et al. 2006). Furthermore, little is known about the contribution of these factors to stem cell function in other species than the mouse, and if the presence of these factors in primary cell cultures enhances the success in establishing SSC lines.

The aim of the current study was to culture and characterize porcine SSCs and to increase our knowledge on the growth factors required for the successful establishment of porcine SSC lines. Neonate porcine testis cells were cultured for nine passages and expression of SSC-specific and somatic genes and proteins were analyzed by quantitative real-time RT-PCR (qRT-PCR) and immunofluorescence. A factorial design experiment in which the presence of commonly used growth factors was tested on primary cell cultures revealed that basic FGF and EGF had considerable influence on colony formation and gene expression patterns. The positive effect of bFGF on somatic cell types potentially impedes successful derivation of porcine SSC lines.

\section{Results}

It has been demonstrated that, after transplantation, porcine male germ cells from neonate testis can colonize a mouse testis that has been depleted by spermatogonia by busulfan treatment (Goel et al. 2008). This demonstrates the stem cell potential of porcine male germ cells and therefore neonate testes were regarded as a valid source for the current study. Seminiferous tubules from neonatal pig testes were dissociated (Fig. 1A) and Nomarski-microscopy revealed the presence of germ cells in the cell suspension, which could be recognized by their high nuclear to cytoplasm ratio and the presence of prominent nucleoli. Cells were then cultured under conditions that have been previously shown to be suitable for the establishment and long-term culture of mouse SSC lines (Kanatsu-Shinohara et al. 2003, 2005). Porcine cell cultures were characterized by investigating the expression of germ cell markers and somatic cell markers of which the expression patterns in testis were known. Dolichos biflorus agglutinin (DBA) is a lectin with carbohydrate specificity towards $\alpha$-linked $N$-acetylgalactosamine and is known to bind specifically to PGCs (Takagi et al. 1997) and to porcine gonocytes and primitive spermatogonia in the neonatal pig testis (Fig. 1B, Goel et al. 2007). Primary cultures of porcine neonate testis cells also contained DBA lectin positive cells (Fig. 1C). However, on the testis sections, some DBA binding to interstitial cells was also observed. Therefore, we also examined the expression of pluripotency-related transcription factor NANOG in cultures of porcine testis cells. It has been previously described that NANOG is expressed in porcine germ cells of the neonate testis (Goel et al. 2008). In the present study, we could confirm this finding. NANOG expression was observed exclusively in germ cells of neonatal testis using immunofluorescence (Fig. 1D). Therefore, NANOG was considered a valid marker and was used to discern germ cells from somatic cells in culture. In the current study, cells that expressed NANOG were observed in primary cell cultures that originated from neonate testis (Fig. 1E and F).

Contrary to male germ cells, Sertoli cells express transcription factor GATA4 (Fig. 1G, Ketola et al. 1999, McCoard et al. 2001), but most cells in the culture were negative for GATA4 (Fig. 1H), which suggests that these cells are not Sertoli cells. Peritubular myoid cells express alpha smooth muscle actin (ASMA; Fig. 1I, Tung \& Fritz 1990), expression of which was observed in primary cultures of porcine neonate testis cells. Cells that did not express ASMA were also observed (Fig. 1J). These results indicate heterogeneity of the cell culture, which was further demonstrated by the presence of three different types of cell colony, each with distinct morphology that could be observed after $\sim 8-14$ days of culture (Fig. 2A, B and E). These colonies were not observed when cells were cultured in MEM-based ES medium, which in contrast with the SSC medium contains a high serum concentration (Fig. 2F). These colonies did not form when the cells were cultured on mitomycin $\mathrm{C}$ treated mouse embryonic fibroblasts (MEFs; data not shown). 
The first type of colony was detected in all cultures and consisted of polygonal cells growing in a monolayer (Fig. 2A). Cells of these colonies stopped proliferating shortly after transplantation of the colonies to new plates and could not be cultured further (data not shown). In these colonies, relative expression levels of $N A N O G$, POU5F1 (OCT4), and GATA4 were lower when compared with the relative expression levels of these genes in neonate testis (Fig. 3). Based on the expression levels, it is concluded that these colonies did not contain germ cells or Sertoli cells.

A second type of cell colony was only present at low numbers and in few cultures. In these colonies individual
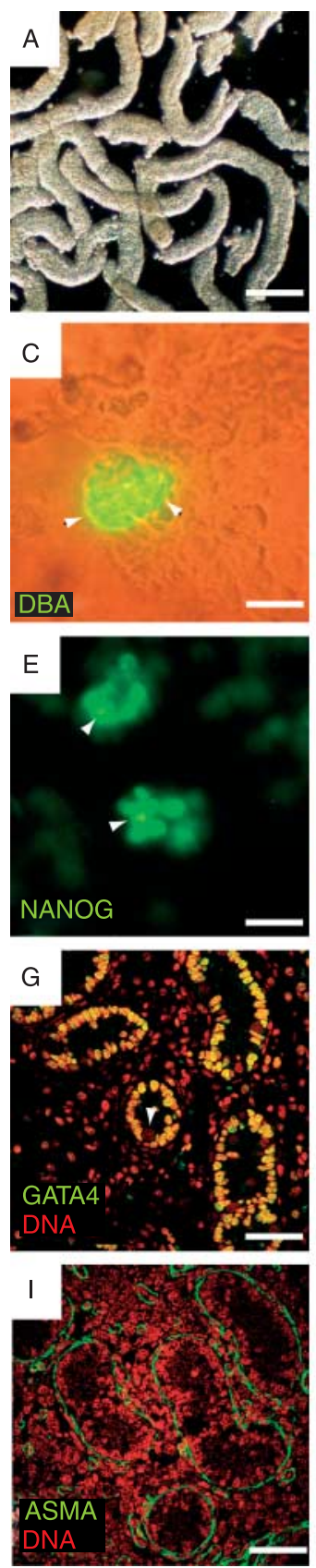
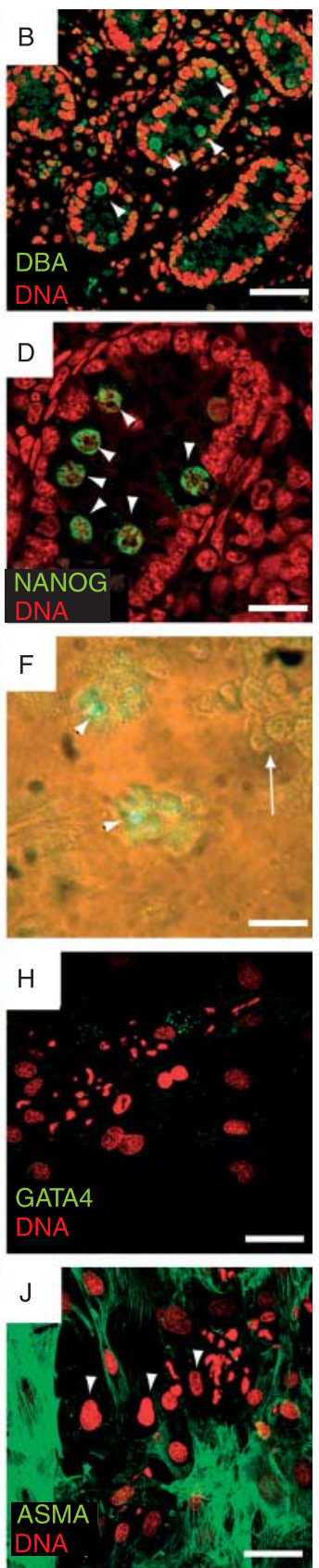

cells were difficult to recognize and, as such, these colonies grew as compact structures that were morphologically comparable to colonies derived from PGCs (Fig. 2B). However, most cells of these colonies did not have alkaline phosphatase activity, which suggests that cells of these colonies are not equivalent to cell cultures derived from PGCs (Fig. 2C and D). Moreover, expression levels of NANOG, POU5F1, and GATA4 were lower in these colonies than in neonate testis (Fig. 3), which indicates that these colonies were not composed of male germ cells or Sertoli cells.

The morphology of yet another colony type consisted of round proliferating cells on top of a monolayer of cells (Fig. 2E). This type of colony was abundant and resembled that of previously described SSC lines (Kanatsu-Shinohara et al. 2003, Kubota et al. 2004, Aponte et al. 2008). These colonies were lost after two to three passages and colony formation was not observed when the cells were transferred to MEFs. Mouse SSCs can be maintained long-term under feeder-free conditions when cultured on laminin coated plates (Kanatsu-Shinohara et al. 2005). We therefore examined the proliferative capacities of the porcine SSC-like colonies when cultured on laminin-coated plates. When cultured on laminin, cells from SSC-like colonies grew in a monolayer. (Fig. 2G). Two SSC-like colonies, which originated from different isolations, were cultured for nine passages, and were referred to as pGS4 (\#4) and pGS6 (\#6). Every 4-6 days, approximately one-third of the cells were transferred to new laminin-coated plates when cultures reached $50-70 \%$ confluency. After nine passages, proliferation was reduced and cell culture was stopped.

The cell lines were further characterized by their gene expression patterns using qRT-PCR. Both cell lines expressed genes that are also expressed by porcine neonatal male germ cells and SSCs (Table 1). NANOG is a transcription factor important for pluripotency of cells

Figure 1 Isolation, culture, and characterization of primary cell cultures of porcine neonate testis. (A) Seminiferous tubules from neonate pig testis after the first enzymatic treatment of two-step enzymatic digestion; (B) specific binding of DBA lectin to germ cells in neonate porcine testis, arrowheads denote DBA-lectin-positive germ cells; (C) specific binding of DBA lectin to cells in culture, arrowheads denote DBA-lectin-positive germ cells; (D) expression of NANOG in male germ cells of porcine neonate testis, arrowheads denote NANOGpositive germ cell; (E) expression of NANOG in a group of cells in cell culture of neonate porcine testis, arrowheads denote NANOG-positive cells; (F) brightfield image of NANOG-expressing colony depicted in Fig. 1E, arrowheads denote NANOG-positive cells, arrow denotes NANOG negative cells; (G) expression of GATA4 in Sertoli cells in neonate porcine testis, arrowhead denotes GATA4-negative germ cell; $(\mathrm{H})$ expression of GATA4 in cell culture of neonate porcine testis, most cells were negative; (I) expression of alpha smooth muscle actin (ASMA) in peritubular myoid cells in porcine neonate testis; (J) expression of ASMA in cell culture of neonate porcine testis, arrowheads denote ASMA negative-cells. Scale bars represent: $250 \mu \mathrm{m}$ (A), $100 \mu \mathrm{m}$ (B, G and I), $50 \mu \mathrm{m}(\mathrm{C}-\mathrm{F}, \mathrm{H}$ and $\mathrm{J})$. 

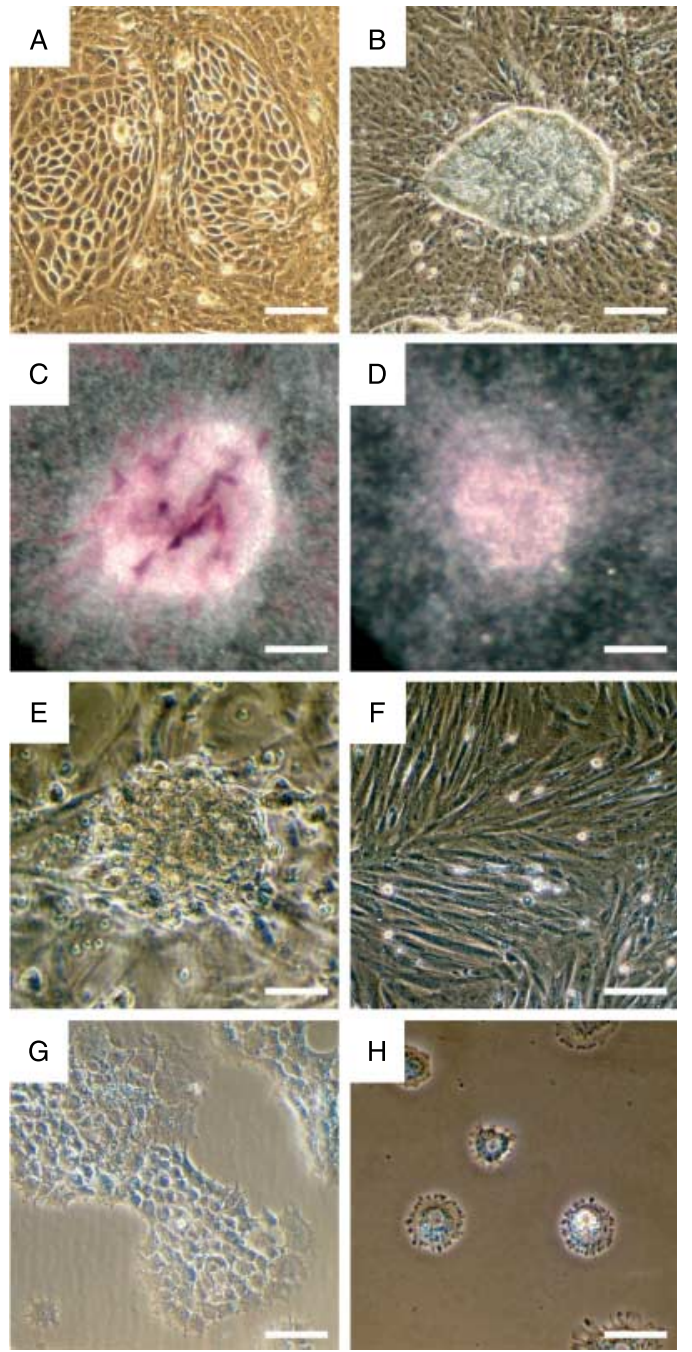

Figure 2 Morphology and characterization of colonies in primary cell cultures of porcine neonate testis. (A) Morphology of polygonal cells growing in a monolayer; (B) primordial germ cell-like colony in cultures of neonate porcine testis cells; (C) alkaline phosphatase activity in primordial germ cell-like colony; (D) negative control (with $5 \mathrm{mM}$ levamisol) for alkaline phosphatase activity in primordial germ cell-like colony; (E) morphology of SSC-like colony in primary cultures of neonate pig testis; (F) morphology of primary neonate porcine testis cells, cultured in ES medium with a high serum concentration, colonies were not observed; (G) morphology of cells of PGS4 at passage 7; (H) morphology of cells of individually picked colonies after growth on laminin-coated plates in absence of growth factors. Scale bars represent: $100 \mu \mathrm{m}(\mathrm{A}, \mathrm{B}$ and $\mathrm{G}), 50 \mu \mathrm{m}(\mathrm{C}, \mathrm{E}, \mathrm{F}$ and H), $75 \mu \mathrm{m}$ (D).

and expression has been demonstrated in germ cells of neonate porcine testis (Chambers et al. 2003, 2007, Mitsui et al. 2003, Goel et al. 2008). NANOG expression levels were higher in pGS4 and pGS6 than in whole neonate testis as determined by qRT-PCR (Table 1 ). Promyelocytic leukemia zinc-finger (PLZF) is a transcriptional repressor expressed in gonocytes and undifferentiated spermatogonia with a role in stem cell self renewal and maintenance of the stem cell pool (Costoya
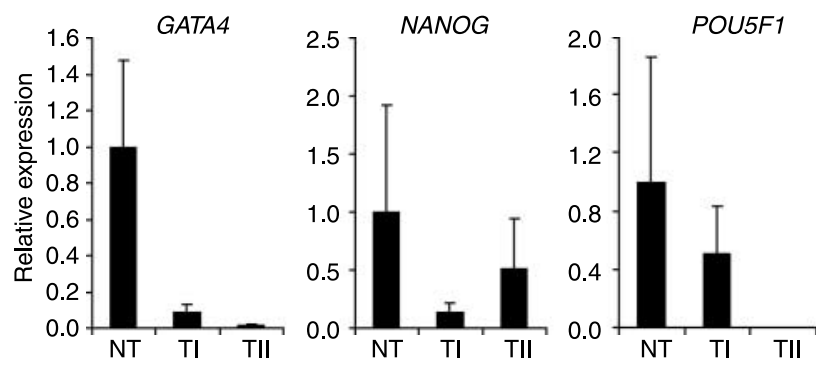

Figure 3 Relative mRNA expression levels of GATA4, NANOG, and POU5F1 in two types of colonies and in neonate porcine testis. For each gene, relative expression in neonate testis (NT) was set to 1 . $\mathrm{T} 1=$ colony type one that consisted of polygonal cells, $\mathrm{TII}=$ colony type two that resembled PGC-colonies and consisted of cells that were difficult to recognize individually.

et al. 2004). PGS4 and pGS6 expressed PLZF at higher levels than whole neonate testis (Table 1). EPCAM is a homophilic adhesion molecule expressed by undifferentiated germ cells and ES cells (Anderson et al. 1999), and indeed Epcam expression has also been reported in mouse SSCs (Kanatsu-Shinohara et al. 2004). EPCAM expression levels were higher in pGS4 and pGS6 than in whole neonate testis (Table 1). POU5F1 is a homeobox transcription factor that plays an important role in pluripotency and in reprogramming somatic cells to a pluripotent state (Nichols et al. 1998, Niwa et al. 2000, Takahashi \& Yamanaka 2006). In the mouse male germ line, POU5F1 expression is maintained from PGCs until their development towards undifferentiated spermatogonia (Ovitt \& Schöler 1998, Pesce et al. 1998, Tadokoro et al. 2002). Porcine gonocytes do not express POU5F1 protein (Goel et al. 2008). In the present study, POU5F1 expression was not detected in pGS4 and relative low levels of expression were observed in pGS6 (Table 1). In the mouse, GDNF signaling through the receptor GFRA1 mediates self-renewal of SSCs (Naughton et al. 2006). Expression levels of GFRA1 were lower in pGS4 and pGS6 than in whole neonate testis. ITGA6, ITGB1, and THY1 are cell surface markers that can be used to enrich for SSCs (Shinohara et al. 1999, Kubota et al. 2003). ITGA6 expression levels were lower in pGS4 and pGS6 than in neonate pig testis and ITGB1-expression levels were approximately equal between testis and cell cultures. In pGS6, THY1 expression was higher than in testis but in pGS4, THY1 expression was lower (Table 1).

When cells were transferred to medium without the growth factors LIF, FGF, EGF, and GDNF, these cells attached, but proliferation was not observed (Fig. 2H). To further determine the effects of different commonly used growth factors in primary cell cultures of porcine testis cells a factorial design experiment was performed. For LIF, GDNF, EGF, and FGF (16 combinations; Table 2) the effects were determined on the number and sizes of SSClike colonies formed in culture. Ten days after culture initiation, low magnification images were made with a 
Table 1 Relative gene expression levels of genes (known to be expressed in mouse or porcine male germ cells) in two cell lines (\#4 at passage 6 and \#6 at passage 3) derived from neonate porcine testis.

\begin{tabular}{lcccccccc}
\hline & NANOG & PLZF & EPCAM & POU5F1 & GFRA1 & ITGA6 & ITGB1 & THY1 \\
\hline Neonate testis & $-/+$ & + & $-/+$ & + & ++ & ++ & + & + \\
Line \#4 & ++ & ++ & ++ & - & $-/+$ & $-/+$ & + \\
Line \#6 & + & + & $+/+$ & $-/+$ & + & + & + & ++
\end{tabular}

For each gene, relative expression was compared to the expression levels in neonate testis (NT). - , no detectable expression; -/+, expression levels were relatively low; + , relatively moderate expression levels; ++ , expression levels were relatively high.

digital camera, which allowed analysis of the numbers and sizes of SSC-like colonies in each condition. EGF and basic FGF both had significant positive effects on the number of colonies and the total area covered by colonies (Fig. 4). Colonies were bigger in the presence of EGF, as demonstrated by the significant effect of this growth factor on the area covered per colony. On the other hand, colonies that were grown in bFGF conditions were relatively smaller compared to those in conditions lacking bFGF (Fig. 4). No effects were detected for LIF and GDNF on the number of colonies or the area covered by these colonies.

Subsequently, the factorial design experiment was continued to determine the effects of growth factors on gene expression levels. We examined the effects of the growth factors on the expression levels of NANOG and $P L Z F$, as indicators of germ cell proliferation. The effect of growth factor conditions on POU5F1 expression was also examined. In pigs, the expression of POU5F1, which is commonly used as marker for pluripotency, is absent in gonocytes (Goel et al. 2008). However, POU5F1 protein is expressed in inner cell masses and trophectoderm of porcine blastocyst stage embryos. Therefore, the expression of this gene was used to determine if a combination of growth factors would establish a more embryonic gene expression profile. Finally, expression levels of GATA4 were determined as indicator for Sertoli cell proliferation.
Basic FGF had a significant negative effect on the expression of the pluripotency gene and pig gonocyte marker NANOG $(P<0.001)$. Relative expression levels of SSC-marker $P L Z F$ were also significantly lower in the presence of bFGF than in the absence of bFGF $(P<0.01)$. Remarkably, expression of pluripotency related POU5F1 was enhanced by FGF $(P<0.001$; Fig. 5). FGF also had strong positive effects on the expression of Sertoli cell marker GATA4 $(P<0.001)$. A two-way interactive effect was detected between EGF and FGF on the expression of GATA4, with EGF reducing the positive influence of FGF on the expression of this gene $(P<0.05$; Fig. 5). Furthermore, a significant positive effect of EGF on the expression of PLZF was observed (Fig. 5).

No other interactive effects of the four growth factors on the expression levels of NANOG, PLZF, GATA4, and POU5F1 were observed. Rather surprisingly, LIF and GDNF did not have detectable effects on the expression levels of NANOG, PLZF, GATA4, and POU5F1 (Fig. 5).

\section{Discussion}

In mammals, gene targeting is largely restricted to mice, for the reason that in these species germline stem cell lines are available such as embryonic and SSC lines. If germline stem cell lines could be established from nonrodent mammals that would greatly facilitate gene targeting in these species. Particularly in pigs, targeted

Table 2 Factorial design: 16 combinations of growth factors were used in primary cell cultures of neonate pig testis.

\begin{tabular}{|c|c|c|c|c|c|c|c|}
\hline & Condition & $\mathbf{a}$ & b & c & d & $\begin{array}{l}\text { Number of } \\
\text { colonies }\end{array}$ & Surface area (pixels) \\
\hline 1 & 0 & 0 & 0 & 0 & 0 & 5 & 7517 \\
\hline 2 & a & a & 0 & 0 & 0 & 8 & 16339 \\
\hline 3 & b & 0 & b & 0 & 0 & 13 & 35697 \\
\hline 4 & $a b$ & $\mathrm{a}$ & b & 0 & 0 & 19 & 11541 \\
\hline 5 & C & 0 & 0 & C & 0 & 17 & 39792 \\
\hline 6 & $\mathrm{ac}$ & $\mathrm{a}$ & 0 & c & 0 & 21 & 52204 \\
\hline 7 & bc & 0 & b & C & 0 & 9 & 26938 \\
\hline 8 & $a b c$ & $\mathrm{a}$ & b & C & 0 & 8 & 37900 \\
\hline 9 & d & 0 & 0 & 0 & d & 37 & 39692 \\
\hline 10 & $\mathrm{ad}$ & a & 0 & 0 & d & 20 & 21144 \\
\hline 11 & bd & 0 & b & 0 & d & 35 & 40525 \\
\hline 12 & $\mathrm{abd}$ & a & b & 0 & d & 36 & 37707 \\
\hline 13 & $\mathrm{~cd}$ & 0 & 0 & C & d & 64 & 89981 \\
\hline 14 & acd & $\mathrm{a}$ & 0 & C & d & 85 & 79531 \\
\hline 15 & bcd & 0 & b & C & d & 63 & 46267 \\
\hline 16 & abcd & $\mathrm{a}$ & b & C & d & 21 & 21992 \\
\hline
\end{tabular}

In this study the factorial design was as follows: $a=$ LIF; $b=$ GDNF; $c=E G F ; d=F G F ; 0=$ growth factor not added. 

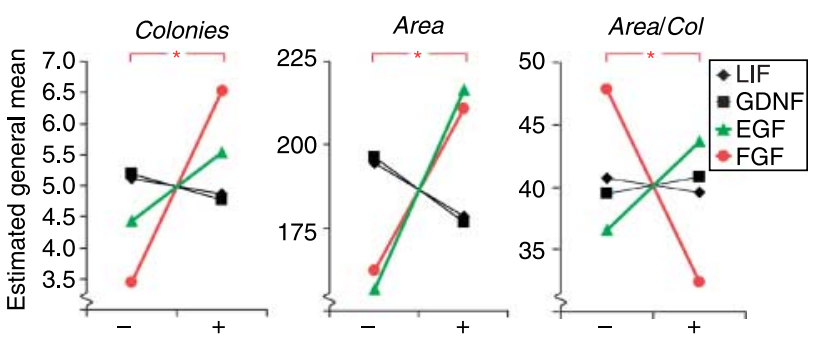

Figure 4 Effects (in estimated general means) of the growth factors LIF, GDNF, EGF, and FGF on the number of colonies (left panel), the total area covered by colonies (middle panel), and the area per colony (right panel) that were present in primary cell cultures from neonate porcine testis after 10 days of culture. $-=$ absence of growth factor, $+=$ presence of growth factor, asterisks denote significant differences between absence or presence of EGF and FGF on colony formation.

mutagenesis would open up manifold opportunities, because of the evident importance of pigs in agriculture but also since pigs are valuable model organisms. However, currently embryonic or SSC lines are not available from this species.

Here, neonate porcine testis cells were cultured under several conditions and characterized. Based on the expression of germ and somatic cell markers it can be concluded that primary cell cultures were composed of mixtures of germ cells and somatic cells. Mouse SSC cultures are also characterized by their heterogeneity.
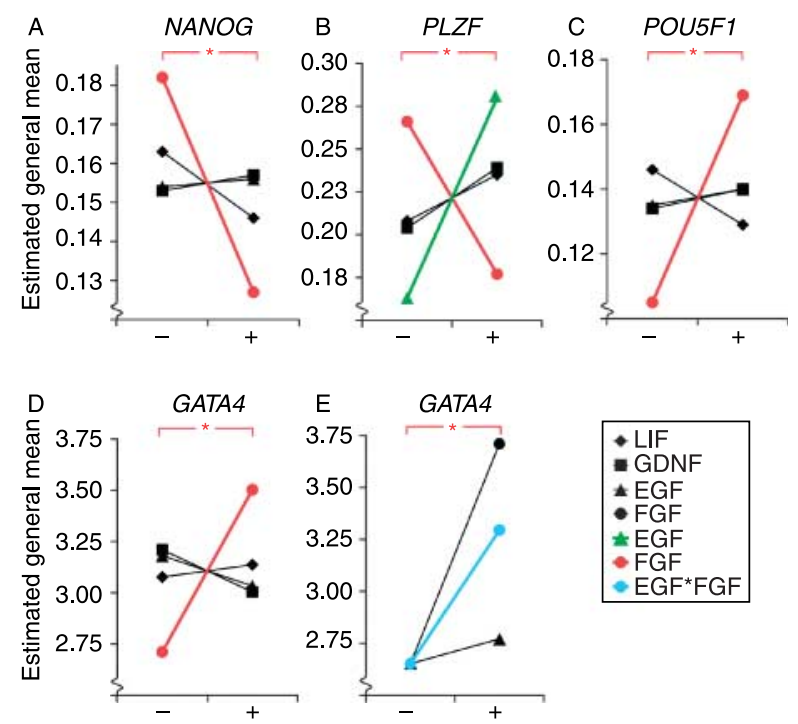

Figure 5 Effects (in estimated general means) of the growth factors LIF, GDNF, EGF, and FGF on gene expression levels. Effect of the growth factors on the expression of (A) NANOG, (B) PLZF, (C) POU5F1,

(D) GATA4 in primary cell cultures from neonate porcine testis. (E) Two way interactive effect (in estimated marginal means) between EGF and FGF on the expression of GATA4 in primary cell cultures from neonate porcine testis. $-=$ absence of growth factor, $+=$ presence of growth factor, (A-D) asterisks denote significant differences between absence or presence of the growth factor on the expression of that particular gene. (E) asterisk denotes significant effect on the expression of GATA4 of EGF in combination with FGF when compared with separate presence of EGF or FGF.
Even though several surface markers have been identified in the mouse that can be used to enrich the number of SSCs using FACS or MACS, e.g. ITGA6, ITGB1, and THY1 (Shinohara et al. 1999, Kubota et al. 2003), none of these markers are restricted to SSCs. As a result, pure populations of SSCs have not yet been described (Oatley \& Brinster 2008).

After 8-14 days of culture in previously described SSC culture conditions (Kanatsu-Shinohara et al. 2003), porcine neonate testis cells gave rise to SSC-like colonies (Fig. 2E). A similar period has been previously described for mouse and bovine SSC-cultures (Kanatsu-Shinohara et al. 2003, Aponte et al. 2008). In bovine cultures, the presence of SSC-like colonies seems to depend on the presence of germ cells (Aponte et al. 2008). In MEMbased ES medium, we did not observe any colonies. This is in contrast with what has been described for bovine cultures, in which colonies were observed when MEM medium was used (Aponte et al. 2008). This difference can be explained by the high concentration of serum in the MEM-based ES medium of the present study. Moreover, in the bovine study, more colonies were formed in SSC medium than in MEM-based medium (Aponte et al. 2008), which is in agreement with the current study.

SSC-like colonies were lost after two to three passages, indicating that the ratio of germ cells:somatic cells declined during culture, as has been previously described for bovine cell cultures (Aponte et al. 2008). When neonate porcine testis cells were cultured on MEFs, colony formation was not observed, which indicates that, under these culture conditions, somatic cells outperformed the germ cells.

From two independent primary cell cultures, SSC-like colonies gave rise to two morphologically similar cell lines. These lines were cultured for nine passages on laminin-coated plates and expressed various SSC markers. Variance in expression levels between both cell lines suggests that these were not equivalent. Especially, in pGS4, expression levels of NANOG, $P L Z F$, and EPCAM were markedly higher than in testis, which indicates that this culture was relatively enriched for germ cells. On the other hand, GFRA1 was expressed at lower levels in both cell lines when compared with the expression levels in neonate testis. In mouse SSCs, it is known that GFRA1 mediates GDNF signaling and thereby supports SSC self-renewal (Naughton et al. 2006). The relatively low expression levels of GFRA1 in the porcine cell cultures could indicate that stem cell numbers are low. Absence of GFRA1 could also explain the lack of effect of GDNF on colony formation and marker gene expression. In the rat testis, expression of GFRA1 is not restricted to the stem cell population (Fouchecourt et al. 2006). Moreover, selection for GFRA1-positive cells in mouse testes will only marginally result in enrichment for SSCs (greater than twofold) when compared with GFRA1-negative cells 
(Buageaw et al. 2005). In the adult mouse testis, GFRA1-positive cells have low stem cell activity (Ebata et al. 2005). The expression pattern of GFRA1 in pig testis is unknown and therefore caution is necessary to use this gene as a marker for SSCs in pigs.

Cells from neonate mouse testes can give rise to SSCs and to pluripotent ES-like cells (Kanatsu-Shinohara et al. 2004, 2008). Successful derivation of such cell lines will greatly depend on the culture conditions. However, the effect of various growth factors on germ cells and somatic cells of heterogeneous primary cultures is largely unknown. Therefore, a factorial design experiment was performed to test the effect of commonly used growth factors on primary cell cultures derived from neonate pig testis.

In presence of EGF the number of colonies and the total area covered by colonies increased. Moreover, in the presence of EGF colonies grew bigger than in conditions without EGF. This is in contrast with previous findings describing a negative effect of EGF on colony size and no effect of EGF on colony numbers (Aponte et al. 2008). However, as suggested by Aponte et al. (2008) such differences could be related to the age, species, cell density, and somatic cell population.

As determined by this factorial design experiment, FGF had a positive effect on the expression of POU5F1 in cell lines derived from neonate pig testes. FGF is an essential ingredient for the establishment of pluripotent EG cell lines from PGCs (Matsui et al. 1992). Furthermore, recent developments have shown that various combinations of the factors C-MYC, SOX2, KLF4, POU5F1, LIN28, and NANOG, can reprogram somatic cells to a pluripotent state. POU5F1 has been a key ingredient for this reprogramming to occur (Takahashi \& Yamanaka 2006, Maherali et al. 2007, Okita et al. 2007, Wernig et al. 2007, Brambrink et al. 2008, Stadtfeld et al. 2008). In the current study, the cell type (s) that showed elevated levels of POU5F1 were not identified.

In the current study, FGF had a negative effect on the expression levels of NANOG, a gene that is expressed in porcine gonocytes. This suggests that FGF impairs selfrenewal of germ cells in primary cell cultures of neonate pig testis. The decrease in expression could be a reflection of the progressive loss of NANOG in gonocytes with increasing age (Goel et al. 2008), even though germ cell numbers increase. Alternatively, it could indicate that proliferation of male germ cells is not supported by FGF and that decreasing NANOG levels are a reflection of a decrease in the proportion of germ cells. However, the latter possibility is less likely, because in primary cultures of neonate testis cells from the rat, FGF had a positive effect on gonocyte proliferation (Van Dissel-Emiliani et al. 1996).

NANOG was used as a marker for porcine male germ cells in this study. However, in the mouse, NANOG is not expressed in gonocytes, but in closely associated to pluripotent cell populations (Chambers et al. 2003,
2007, Mitsui et al. 2003). If NANOG plays a similar role in pluripotency of porcine cells remains to be determined, because in contrast with embryos from the mouse, NANOG does not seem to be expressed in the pluripotent inner cell mass of early porcine blastocysts (Kuijk et al. 2008). Furthermore, NANOG expressing porcine gonocytes can colonize a recipient mouse testis without formation of teratocarcinomas, which is another indication that expression of NANOG in porcine cells does not necessarily reflect pluripotency of these cells (Goel et al. 2008). Nevertheless, the observed decrease in expression levels of NANOG in primary cell cultures with FGF indicates that cells which have an expression program related to neonatal porcine male germ cells are progressively lost upon FGF signaling.

FGF also enhanced the expression of Sertoli cell marker GATA4. In a previous study, FGF has been identified as a potent mitogen of Sertoli cells (Jaillard et al. 1987, Van Dissel-Emiliani et al. 1996). Therefore, the enhanced levels of GATA4 expression are most probably caused by increased proliferation of Sertoli cells. EGF has also been described as a weak mitogen of Sertoli cells (Jaillard et al. 1987). In the current study, a one-way effect of EGF on GATA4 expression was not detected. Cells cultured in the presence of EGF and FGF expressed lower levels of GATA4 than cells cultured with FGF alone. In other words, EGF partially eliminated the positive influence of FGF on GATA4 expression. These findings suggests that for the isolation and culture of germ cells in the presence of FGF, addition of EGF can partially prevent the mitogenic effect of FGF on Sertoli cells, thereby limiting the contribution of this somatic cell type to the culture.

Remarkably, despite the power of using factorial designs in determining possible effects, GDNF and LIF did not affect the expression of NANOG, POU5F1, GATA4, or PLZF in primary cell cultures of pig neonate testis. Especially, for GDNF this is rather surprising, because GFRA1, the receptor that mediates GDNF signaling, is expressed in neonate testis as determined by RT-PCR (Table 1). The porcine gene GFRA 1 codes for a protein that has $94 \%$ identity with rat GFRA 1 and 15 of the 28 amino acids that are different in pig GFRA1 are also present in human GFRA1. Just 13 amino acids $(2.8 \%)$ are not present in rat or human. Because rat GDNF is known to cross-react with human it is unlikely that rat GDNF cannot bind porcine GFRA1. Therefore, the lack of effect of GDNF in porcine testis cell cultures suggests that the initial increase of germ cells and Sertoli cells that can be observed in pig testis from birth onwards (Franca et al. 2000), does not depend on GDNF signaling. Porcine male germ cells express PLZF and NANOG and are positive for DBA lectin shortly after birth, but expression of PLZF and NANOG and DBA lectin affinity are progressively lost within the first few weeks after birth (Goel et al. 2007, 2008). The correlation between age and the expression of PLZF 
and NANOG demonstrates that porcine germ cells experience dynamic changes between birth and puberty. Likewise, the responsiveness of male porcine germ cells towards GDNF might also increase between birth and puberty. A recent report describes the positive effects of GDNF on germ cell numbers in bovine SSC cultures (Aponte et al. 2008). The sources of these bovine SSC cultures were testes from calves aged 4 to 6 months. Given the close relationship between cow and pig, it would be interesting to determine if GDNF has an effect on porcine germ cells that are derived from animals of an older age than used in the current study.

Recent studies demonstrate the importance of growth factors on stem cell behavior. Derivation of pluripotent cells from male germ cells is enhanced by the cytokine insulin-like growth factor-1 (IGF1; Huang et al. 2009) and addition of CSF1 to in vitro cultures enhanced SSC self renewal (Oatley et al. 2009). Consequently, addition of CSF1 may facilitate the establishment of porcine germ cell cultures, whereas addition of IGF1 could help in the generation of pluripotent cell lines from porcine germ cell cultures. A factorial design experiment as conducted in the current study could help dissect the effect of growth factors such as CSF1 and IGF1 on porcine germ cell cultures.

Based on the potential of porcine germ cells to form colonies after transplantation, we assumed that the mechanism of self-renewal for these cells is conserved between species and that mouse SSC culture conditions could be applied for the derivation of porcine germ line stem cells. Here, we used the power of a factorial design to investigate the effects of LIF, GDNF, EGF, and FGF on primary cell cultures of pig neonate testis. We demonstrate that EGF and FGF had a large influence on the formation of SSC-like colonies and on gene expression patterns in these cultures. Putative positive effects of these growth factors on germ cell self-renewal seemed to be diluted by the positive effects these growth factors had on somatic cells. Future studies could use a similar approach, in combination with a functional assay such as xenogeneic transplantation to further analyze the effects of growth factor combinations on stem cell proliferation.

\section{Materials and Methods \\ Cell isolation and cell culture}

Pig (Sus scrofa) testes of a mixed breed were obtained from day 3 to day 4 neonate piglets that underwent routine castration under local anesthesia at the farm 'de Tolakker' of the Faculty of Veterinary Medicine, Utrecht University. After collection in Hank's balanced salt solution (HBSS; Invitrogen), the tunica was removed and minced testis sections were treated for 15-30 min with $1 \mathrm{mg} / \mathrm{ml}$ hyaluronidase, $1 \mathrm{mg} / \mathrm{ml}$ collagenase type IV, and $1.4 \mathrm{mg} / \mathrm{ml}$ DNAse (all from Sigma-Aldrich) in HBSS at $37^{\circ} \mathrm{C}$. After washing with HBSS, the cells were treated for an additional $15 \mathrm{~min}$ with $1 \mathrm{mg} / \mathrm{ml}$ collagenase type IV and $1.4 \mathrm{mg} / \mathrm{ml}$ DNAse at $37^{\circ} \mathrm{C}$. Again, the cells were washed with HBSS and subsequently treated for 4 min with trypsin EDTA (Invitrogen) supplemented with $1.4 \mathrm{mg} / \mathrm{ml}$ DNAse. Next, enzymatic activity was blocked by addition of Iscove's modified DMEM (Sigma) with 0.5\% BSA (Sigma-Aldrich). The resulting cell suspension was filtered with a $40 \mu \mathrm{m}$ filter (BD Falcon, Erembodegem, Belgium) before culture. The cells were preplated on gelatin-coated culture plates by overnight incubation. The next day, floating cells were passaged to secondary culture plates that were not treated with gelatin. Cells were cultured in StemPro-34 SFM (Invitrogen) supplemented with StemPro Supplement (Invitrogen), $25 \mu \mathrm{g} / \mathrm{ml}$ insulin (Sigma), $100 \mu \mathrm{g} / \mathrm{ml}$ transferrin (Sigma), $60 \mu \mathrm{M}$ putrescine (Sigma), $30 \mu \mathrm{M}$ sodium selenite (Sigma), $6 \mathrm{mg} / \mathrm{ml}$ D-(+)-glucose (Merck), $30 \mathrm{mg} / \mathrm{ml}$ pyruvic acid (Sigma), $1 \mu \mathrm{l} / \mathrm{ml}$ DL-lactic acid (Sigma), $5 \mathrm{mg} / \mathrm{ml} \mathrm{BSA} \mathrm{(Sigma),} 2 \mathrm{mM}$ L-glutamine (Sigma), $5 \times 10^{-5}$ M 2-mercaptoethanol (Sigma), MEM vitamin solution (Invitrogen), MEM non-essential amino acids (Invitrogen), $10^{-4} \mathrm{M}$ ascorbic acid (Sigma), $10 \mu \mathrm{g} / \mathrm{ml}$ D-biotin (Sigma), $30 \mathrm{ng} / \mathrm{ml}$ b-estradiol (Sigma), $60 \mathrm{ng} / \mathrm{ml}$ progesterone (Sigma), 1\% FCS (Sigma), and the growth factors murine LIF $\left(10^{3} \mathrm{U} / \mathrm{ml}\right)$, GDNF $(10 \mathrm{ng} / \mathrm{ml})$, EGF $(20 \mathrm{ng} / \mathrm{ml})$, and bFGF $(10 \mathrm{ng} / \mathrm{ml}$; Kanatsu-Shinohara et al. 2003). The cells were cultured on autologous feeders, MEFs or laminin-coated plates (Kanatsu-Shinohara et al. 2005). Porcine cells from neonate testes were also cultured in mouse ES cell medium, which consisted of GMEM (Invitrogen), supplemented with $2 \mathrm{mM}$ L-glutamine, $1 \times$ non-essential amino acids (Invitrogen), $0.1 \mathrm{mM} \beta$-mercaptoethanol, $1 \mathrm{mM}$ sodium pyruvate, $10 \%$ fetal bovine serum and LIF.

For the factorial design experiment, freshly isolated cells were plated on gelatin-coated plates in standard SSC medium without growth factors or with any combination of LIF, GDNF, EGF, or FGF (Table 2). The following day, unattached cells were transferred to uncoated plates. Every other day, half of the medium was replaced by fresh medium supplemented with the same combination of growth factors. After ten days, digital images were made, cultures were terminated and RNA was isolated with Trizol as described below. The entire factorial design experiment was repeated once.

\section{Immunohistochemistry, immunofluorescence, confocal laser scanning microscopy, and AP staining}

For immunofluorescence on testis sections, testis tissue was fixed overnight $(\mathrm{o} / \mathrm{n})$ in $4 \%$ paraformaldehyde (PFA) and embedded in paraffin the following day. Sections were cut at 5-7 $\mu \mathrm{m}$ and mounted on superfrost plus slides (Menzel, Braunschweig, Germany), which were dried o/n at $37{ }^{\circ} \mathrm{C}$. For immunofluorescence, slides were deparaffinized in xylol and subjected to antigen retrieval by boiling the slides for $10 \mathrm{~min}$ in citrate buffer at $\mathrm{pH}$ 6. Following antigen retrieval, slides were permeabilized in TBS with $0.05 \%$ tween (TBST) and with TritonX100 (0.1\%). Permeabilized slides were blocked for $1 \mathrm{~h}$ in TBST with $0.5 \%$ BSA (Sigma-Aldrich) followed by $\mathrm{o} / \mathrm{n}$ incubation with the primary antibody (Table 3) in blocking solution at $4{ }^{\circ} \mathrm{C}$. The following day, slides were incubated in the 
Table 3 Antibodies used for immunofluorescence on porcine cells.

\begin{tabular}{llcc}
\hline Immunogen & Source & Dilution & Description \\
\hline Full length mouse NANOG fusion protein & Abcam, Cambridge, UK (AB21603) & $1: 100$ & Rabbit polyclonal \\
AA328-439 of human GATA4 & Santa Cruz Biotechnology, Santa Cruz, CA, USA (sC-9053) & $1: 100$ & Rabbit polyclonal \\
N-terminal human ASMA & DAKO, Heverlee, Belgium (M0851) & $1: 70$ & Mouse monoclonal \\
\hline
\end{tabular}

AA, amino acids.

secondary antibody in blocking solution for $1 \mathrm{~h}$ at $4{ }^{\circ} \mathrm{C}$, after which the slides were counterstained with TOPRO-3 (Invitrogen) and mounted in Vectashield.

Cells were cultured on chamberslides (LabTek/Nunc, Roskilde, Denmark) and subsequently fixed in cold methanol for $5 \mathrm{~min}$, washed for $5 \mathrm{~min}$ in ice-cold acetone, and from there on, the above described staining procedure continued from the permeabilization step onwards. Fluorescent images were retrieved with a digital camera mounted on an epifluorescence microscope and with a Confocal Laser Scanning Microscope (Bio-Rad).

The presence of cells reactive to DBA lectin was determined by incubating slides with FITC-labeled DBA lectin (Sigma) immediately after antigen retrieval. Cultured cells were incubated in FITC-labeled DBA lectin immediately after fixation with $4 \%$ PFA. For alkaline phosphatase activity detection, cells were fixed for $30 \mathrm{~min}$ in $4 \%$ PFA and subsequently incubated in $2 \% \mathrm{NBT} / \mathrm{BCIP}$ (Roche) diluted in $0.1 \mathrm{M}$ Tris- $\mathrm{HCl}(\mathrm{pH} 9.5)$ with $0.1 \mathrm{M} \mathrm{NaCl}$. As negative controls, cells were incubated in $2 \% \mathrm{NBT} / \mathrm{BCIP}$ diluted in $0.1 \mathrm{M}$ Tris- $\mathrm{HCl}(\mathrm{pH} 9.5)$ with $0.1 \mathrm{M}$ $\mathrm{NaCl}$ and $5 \mathrm{mM}$ levamisole (Sigma).

\section{RNA extraction, $R T$, and quantitative real time PCR}

RNA from neonate testis and cell cultures was isolated with Trizol (Invitrogen), according to the manufacturer's instructions. In an additional purification step immediately following phase separation, one volume of phenol:chloroform:isoamyl alcohol (Fluka, Sigma-Aldrich) was added to the aqueous phase. Subsequently, samples were mixed, incubated at room temperature (RT) for 5 min, centrifuged and incubated at RT for an additional $5 \mathrm{~min}$. The aqueous phase was transferred to a new tube and put on ice. From here, the Trizol RNA isolation procedure was resumed, from the RNA precipitation step onwards. RNA was treated with $2 \mu \mathrm{l}$ DNAse $(2.75$ Kunitz units/ $\mu$ l; Qiagen) for $20 \mathrm{~min}$ at $37^{\circ} \mathrm{C}$, after which the enzyme was inactivated by incubation at $65^{\circ} \mathrm{C}$ for $10 \mathrm{~min}$. Synthesis of cDNA was primed with random primers and RNA samples were reverse transcribed with Superscript III (Invitrogen) according to the company's instructions. For each RNA sample an equivalent mixture was prepared, from which Superscript III was omitted, to control for genomic DNA contamination. After cDNA synthesis, samples were stored at $-20^{\circ} \mathrm{C}$ before they were used in PCRs. Relative quantification of transcript levels was performed as previously described (Kuijk et al. 2007). Primers were designed with Beacon Designer 4 (PREMIER Biosoft International, Palo Alto, CA, USA; Table 4). In all samples, the expression levels of four housekeeping genes (BACT, B2M, $G A P D H$, and $P G K 1$ ) were examined with geNorm, to determine which of these housekeeping genes were stably expressed in all conditions (Vandesompele et al. 2002). BACT was the least stable gene and $B 2 M$ and $P G K 1$ were the most stable genes. Therefore, these latter two genes were used as reference genes for the normalization of qRT-PCR data. For each sample, - RT negative controls were used in all reactions to exclude the possibility of mistaking genomic DNA for transcripts. The amplicons $(10 \mu \mathrm{l})$ were run on $1 \%$ agarose gels and primer specificity was confirmed by sequencing of the products.

\section{Statistical analysis}

Data obtained with the factorial design were analyzed with SPSS v.15 software (SPSS, Chicago, IL, USA). A square root transformation was carried out on the expression data of NANOG, PLZF, GATA4, and POU5F1, after which these values displayed a normal distribution. Subsequently, a mixed model analysis determined the effects of the different growth factors on the expression levels of the different genes. The effects were visualized by displaying the estimated marginal means for the absence and presence of each growth factor.

Table 4 Primers used for RT-PCR and quantitative real-time RT-PCR on porcine cells.

\begin{tabular}{|c|c|c|c|}
\hline Gene & Forward primer & Reverse primer & $T$ \\
\hline NANOG & 5'-CСТССАTGGATCTGCTTATTC-3' & 5'-САTСTGСTGGAGGCTGAGGT-3' & 63.0 \\
\hline$P L Z F$ & 5'-AAAGCGGTTCCTGGATAGTTTG-3' & 5'-GGTCTGCCTGTGTGTCTCC-3' & 54.4 \\
\hline EPCAM & 5'-ACCAGAGAATGCTATCCAGAAC- $3^{\prime}$ & 5'-СТСАСТСGСТССАAACAGG-3' & 53.0 \\
\hline POU5F1 & 5'-GTTCTCTTTGGGAAGGTGTT-3' & $5^{\prime}$-ACACGCGGACCACATCCTTC-3' & 55.4 \\
\hline GFRA1 & 5'-ATAGACTCTAGTAGCCTCAG-3' & 5'-AGGGACTTGTTCTTGACC-3' & 53.8 \\
\hline ITGA6 & $5^{\prime}$-AAACGAGAAATTGCTGAAAGAC-3' & 5'-CACTAGAATGATCCACCAAGG-3' & 54.5 \\
\hline ITGB1 & 5'-ATGAGGAGGATTACTTCAGACTTC-3' & 5'-GCAGCCGTGTCACATTCC-3' & 53.2 \\
\hline THY1 & 5'-TCTCTTGCTAACAGTCTTG-3' & 5'-GGTAGTGAAGCCTGATAAG-3' & 54.4 \\
\hline$B 2 M$ & 5'-TTCACACCGCTCCAGTAG-3' & 5'-CCAGATACATAGCAGTTCAGG-3' & 59.5 \\
\hline$B A C T$ & 5'-CATCACCATCGGCAACGAGC-3' & 5'-TAGAGGTCCTTGCGGATGTC-3' & 55.8 \\
\hline GAPDH & $5^{\prime}$-TCGGAGTGAACGGATTTG- $3^{\prime}$ & $5^{\prime}$-CCTGGAAGATGGTGATGG-3' & 51.1 \\
\hline$P G K 1$ & $5^{\prime}$-AGATAACGAACAACCAGAGG- $3^{\prime}$ & 5'-TGTCAGGCATAGGGATACC-3' & 56.4 \\
\hline
\end{tabular}

Primers for NANOG, POU5F1, B2M, BACT, GAPDH, and PGK1 have also been used in previous studies Kuijk et al. (2007, 2008). 


\section{Declaration of interest}

The authors declare no conflict of interest associated with the content of this study.

\section{Funding}

This research did not receive any specific grant from any funding agency in the public, commercial, or not-for-profit sector.

\section{Author contribution statement}

E W Kuijk was the primary author for the manuscript. B Colenbrander and B A J Roelen supervised the study design. B A J Roelen also supervised analyses and writing.

\section{Acknowledgements}

We would like to thank Hans Vernooij from the department of Farm Animal Health, Faculty of Veterinary Medicine in Utrecht, who assisted in the statistical analysis of the factorial design experiment. Furthermore, we would like to acknowledge Jan van Mourik from 'De Tolakker' for kindly providing surplus pig testes. Confocal laser scanning microscopy was performed at the Center for Cell Imaging at the Faculty of Veterinary Medicine in Utrecht with the help of Ir Anko de Graaff and Dr Richard Wubbolts. We are also grateful to Federica van Dissel-Emiliani, for her help in isolating seminiferous tubuli from pig testes.

\section{References}

Anderson R, Schaible K, Heasman J \& Wylie C 1999 Expression of the homophilic adhesion molecule, Ep-CAM, in the mammalian germ line. Journal of Reproduction and Fertility 116 379-384.

Aponte PM, Soda T, Teerds KJ, Mizrak SC, van de Kant HJ \& Derooij DG 2008 Propagation of bovine spermatogonial stem cells in vitro. Reproduction 136 543-557.

Brambrink T, Foreman R, Welstead GG, Lengner CJ, Wernig M, Suh H \& Jaenisch R 2008 Sequential expression of pluripotency markers during direct reprogramming of mouse somatic cells. Cell Stem Cell 2 151-159.

Brinster RL 2002 Germline stem cell transplantation and transgenesis. Science $2962174-2176$.

Buageaw A, Sukhwani M, Ben-Yehudah A, Ehmcke J, Rawe VY, Pholpramool C, Orwig KE \& Schlatt S 2005 GDNF family receptor alpha1 phenotype of spermatogonial stem cells in immature mouse testes. Biology of Reproduction 73 1011-1016.

Chambers I, Colby D, Robertson M, Nichols J, Lee S, Tweedie S \& Smith A 2003 Functional expression cloning of Nanog, a pluripotency sustaining factor in embryonic stem cells. Cell 113 643-655.

Chambers I, Silva J, Colby D, Nichols J, Nijmeijer B, Robertson M, Vrana J, Jones K, Grotewold L \& Smith A 2007 Nanog safeguards pluripotency and mediates germline development. Nature 450 1230-1234.

Costoya JA, Hobbs RM, Barna M, Cattoretti G, Manova K, Sukhwani M, Orwig KE, Wolgemuth DJ \& Pandolfi PP 2004 Essential role of Plzf in maintenance of spermatogonial stem cells. Nature Genetics 36 653-659.

Van Dissel-Emiliani FM, De Boer-Brouwer M \& De Rooij DG 1996 Effect of fibroblast growth factor-2 on Sertoli cells and gonocytes in coculture during the perinatal period. Endocrinology 137 647-654.

Dobrinski I 2005 Germ cell transplantation and testis tissue xenografting in domestic animals. Animal Reproduction Science 89 137-145.

Ebata K, Zhang X \& Nagano MC 2005 Expression patterns of cell-surface molecules on male germ line stem cells during postnatal mouse development. Molecular Reproduction and Development 72 171-181.
Fouchecourt S, Godet M, Sabido O \& Durand P 2006 Glial cell-linederived neurotropic factor and its receptors are expressed by germinal and somatic cells of the rat testis. Journal of Endocrinology 190 59-71.

Franca LR, Silva VA Jr, Chiarini-Garcia H, Garcia SK \& Debeljuk L 2000 Cell proliferation and hormonal changes during postnatal development of the testis in the pig. Biology of Reproduction 63 1629-1636.

Goel S, Sugimoto M, Minami N, Yamada M, Kume S \& Imai H 2007 Identification, isolation, and in vitro culture of porcine gonocytes. Biology of Reproduction 77 127-137.

Goel S, Fujihara M, Minami N, Yamada M \& Imai H 2008 Expression of NANOG, but not POU5F1, points to the stem cell potential of primitive germ cells in neonatal pig testis. Reproduction 135 785-795.

Guan K, Nayernia K, Maier LS, Wagner S, Dressel R, Lee JH, Nolte J, Wolf F, Li M, Engel W et al. 2006 Pluripotency of spermatogonial stem cells from adult mouse testis. Nature 440 1199-1203.

Huang YH, Chin CC, Ho HN, Chou CK, Shen CN, Kuo HC, Wu TJ, Wu YC, Hung YC, Chang CC et al. 2009 Pluripotency of mouse spermatogonial stem cells maintained by IGF-1-dependent pathway. FASEB Journal $232076-2087$.

Jaillard C, Chatelain PG \& Saez JM 1987 In vitro regulation of pig Sertoli cell growth and function: effects of fibroblast growth factor and somatomedin-C. Biology of Reproduction 37 665-674.

Kanatsu-Shinohara M, Ogonuki N, Inoue K, Miki H, Ogura A, Toyokuni S \& Shinohara T 2003 Long-term proliferation in culture and germline transmission of mouse male germline stem cells. Biology of Reproduction 69 612-616.

Kanatsu-Shinohara M, Inoue K, Lee J, Yoshimoto M, Ogonuki N, Miki H, Baba S, Kato T, Kazuki Y, Toyokuni S et al. 2004 Generation of pluripotent stem cells from neonatal mouse testis. Cell 119 1001-1012.

Kanatsu-Shinohara M, Miki H, Inoue K, Ogonuki N, Toyokuni S, Ogura A \& Shinohara T 2005 Long-term culture of mouse male germline stem cells under serum-or feeder-free conditions. Biology of Reproduction 72 985-991.

Kanatsu-Shinohara M, Ikawa M, Takehashi M, Ogonuki N, Miki H, Inoue K, Kazuki Y, Lee J, Toyokuni S, Oshimura M et al. 2006 Production of knockout mice by random or targeted mutagenesis in spermatogonial stem cells. PNAS 103 8018-8023.

Kanatsu-Shinohara M, Lee J, Inoue K, Ogonuki N, Miki H, Toyokuni S, Ikawa M, Nakamura T, Ogura A \& Shinohara T 2008 Pluripotency of a single spermatogonial stem cell in mice. Biology of Reproduction $\mathbf{7 8}$ 681-687.

Ketola I, Rahman N, Toppari J, Bielinska M, Porter-Tinge SB, Tapanainen JS, Huhtaniemi IT, Wilson DB \& Heikinheimo M 1999 Expression and regulation of transcription factors GATA-4 and GATA-6 in developing mouse testis. Endocrinology 140 1470-1480.

Kubota H, Avarbock MR \& Brinster RL 2003 Spermatogonial stem cells share some, but not all, phenotypic and functional characteristics with other stem cells. PNAS 100 6487-6492.

Kubota H, Avarbock MR \& Brinster RL 2004 Growth factors essential for self-renewal and expansion of mouse spermatogonial stem cells. PNAS 101 16489-16494.

Kuijk EW, du Puy L, van Tol HT, Haagsman HP, Colenbrander B \& Roelen BA 2007 Validation of reference genes for quantitative RT-PCR studies in porcine oocytes and preimplantation embryos. BMC Developmental Biology 758.

Kuijk EW, Du Puy L, Van Tol HT, Oei CH, Haagsman HP, Colenbrander B \& Roelen BA 2008 Differences in early lineage segregation between mammals. Developmental Dynamics 237 918-927.

Maherali N, Sridharan R, Xie W, Utikal J, Eminli S, Arnold K, Stadtfeld M, Yachechko R, Tchieu J, Jaenisch R et al. 2007 Directly reprogrammed fibroblasts show global epigenetic remodeling and widespread tissue contribution. Cell Stem Cell 1 55-70.

Matsui Y, Zsebo K \& Hogan BL 1992 Derivation of pluripotential embryonic stem cells from murine primordial germ cells in culture. Cell $\mathbf{7 0}$ 841-847.

McCoard SA, Wise TH, Fahrenkrug SC \& Ford JJ 2001 Temporal and spatial localization patterns of Gata4 during porcine gonadogenesis. Biology of Reproduction 65 366-374.

McLaren A 2003 Primordial germ cells in the mouse. Developmental Biology 262 1-15. 
Mitsui K, Tokuzawa Y, Itoh H, Segawa K, Murakami M, Takahashi K, Maruyama M, Maeda M \& Yamanaka S 2003 The homeoprotein Nanog is required for maintenance of pluripotency in mouse epiblast and ES cells. Cell 113 631-642.

Naughton CK, Jain S, Strickland AM, Gupta A \& Milbrandt J 2006 Glial cell-line derived neurotrophic factor-mediated RET signaling regulates spermatogonial stem cell fate. Biology of Reproduction 74 314-321.

Nichols J, Zevnik B, Anastassiadis K, Niwa H, Klewe-Nebenius D, Chambers I, Scholer H \& Smith A 1998 Formation of pluripotent stem cells in the mammalian embryo depends on the POU transcription factor Oct4. Cell 95 379-391.

Niwa H, Miyazaki J \& Smith AG 2000 Quantitative expression of Oct-3/4 defines differentiation, dedifferentiation or self-renewal of ES cells. Nature Genetics 24 372-376.

Oatley JM \& Brinster RL 2008 Regulation of spermatogonial stem cell selfrenewal in mammals. Annual Review of Cell and Developmental Biology 24 263-286.

Oatley JM, Oatley MJ, Avarbock MR, Tobias JW \& Brinster RL 2009 Colony stimulating factor 1 is an extrinsic stimulator of mouse spermatogonial stem cell self-renewal. Development 136 1191-1199.

Okita K, Ichisaka T \& Yamanaka S 2007 Generation of germline-competent induced pluripotent stem cells. Nature 448 313-317.

Ovitt C \& Schöler HR 1998 The molecular biology of Oct-4 in the early mouse embryo. Molecular Human Reproduction 4 1021-1031.

Pesce M, Gross MK \& Schöler HR 1998 In line with our ancestors: Oct-4 and the mammalian germ. Bioessays 20 722-732.

Shinohara T, Avarbock MR \& Brinster RL 1999 Beta1- and alpha6-integrin are surface markers on mouse spermatogonial stem cells. PNAS $\mathbf{9 6}$ 5504-5509.
Stadtfeld M, Brennand K \& Hochedlinger K 2008 Reprogramming of pancreatic beta cells into induced pluripotent stem cells. Current Biology 18 890-894.

Tadokoro Y, Yomogida K, Ohta H, Tohda A \& Nishimune Y 2002 Homeostatic regulation of germinal stem cell proliferation by the GDNF/FSH pathway. Mechanisms of Development 113 29-39.

Takagi Y, Talbot NC, Rexroad CE Jr \& Pursel VG 1997 Identification of pig primordial germ cells by immunocytochemistry and lectin binding. Molecular Reproduction and Development 46 567-580.

Takahashi K \& Yamanaka S 2006 Induction of pluripotent stem cells from mouse embryonic and adult fibroblast cultures by defined factors. Cell 126 663-676.

Tung PS \& Fritz IB 1990 Characterization of rat testicular peritubular myoid cells in culture: alpha-smooth muscle isoactin is a specific differentiation marker. Biology of Reproduction 42 351-365.

Vandesompele J, De Preter K, Pattyn F, Poppe B, Van Roy N, De Paepe A \& Speleman F 2002 Accurate normalization of real-time quantitative RT-PCR data by geometric averaging of multiple internal control genes. Genome Biology 3 research0034.1-research0034.11.

Wernig M, Meissner A, Foreman R, Brambrink T, Ku M, Hochedlinger $K$, Bernstein BE \& Jaenisch R 2007 In vitro reprogramming of fibroblasts into a pluripotent ES-cell-like state. Nature 448 318-324.

Received 14 April 2009

First decision 20 May 2009

Revised manuscript received 7 July 2009

Accepted 24 July 2009 